\title{
Cationic Electrodeposition of Solvent-Soluble Polyimide with Pendant Dimethylaminobenzoyloxy Groups and Evaluation of Its Thermostability
}

\author{
Ayumi Kobayashi ${ }^{1 *}$, Misaki Sou ${ }^{1}, K_{0 h e i} \operatorname{Iritani}^{1}$, Seiji Bando ${ }^{2}$, and \\ Takashi Yamashita $^{1^{* *}}$ \\ ${ }^{1}$ Department of Applied Chemistry, School of Engineering, \\ Tokyo University of Technology, 1404-1 Katakura, Hachioji, Tokyo 192-0982, Japan \\ ${ }^{2}$ Material Development Laboratory, Sumitomo Seika Chemicals Co. Ltd., \\ 346-1 Miyanishi, Harima-cho, Kako-gun, Hyogo 675-0145, Japan \\ *re160038b@edu.teu.ac.jp \\ **yamashitatks@stf.teu.ac.jp
}

\begin{abstract}
Owing to the paradigm shift in the development and utilization of energy systems from petroleum to electricity under social trend to realize sustainable society, the development of high-performance electrical devices has become increasingly important. Insulating materials are one of the key technologies for the practical application of next-generation electric devices because they must be driven at higher voltages but their complex shapes cannot be coated using current coating techniques. Therefore, the development of insulating materials with thermostability and facile electrodeposition ability is crucial for the production of high-performance next-generation electric devices. In this study, synthesis of novel polyimide with pendant dimethylaminobeonzoyloxy groups is described, with which hybrid electrodeposition coating with boehmite alumina was successfully obtained whose $10 \%$ weight loss temperature was $380^{\circ} \mathrm{C}$.
\end{abstract}

Keywords: Electrodeposition, Polyimide, Hybrid coating, Boehmite alumina, Cation

\section{Introduction}

The development of high-performance electrical devices has become increasingly important nowadays owing to the paradigm shift in the energy systems from petroleum to electricity under social trend to sustainable society. As an example, demand of electric vehicles will increase more and more. Although their conventional motors, in which the power is defined as the product of electric current and voltage, are driven by voltage of $700 \mathrm{~V}$, the next-generation standard of electric voltage is expected to become much higher, because electric current cannot increase due to the problems caused by Joule heating. Accordingly, next-generation insulating materials, which have excellent thermostability and strong resistance against electric surges induced by inverter circuits are required to prevent their degradation and breakdown [1]. Recently, an advance in electric motors with novel shapes is attracting much attention by their high performance [2]. Conventional electric motor coils are fabricated by winding enamel wires around iron cores, where the enamel wires consist of copper wire insulated by poly(amide imide) (PAI) or polyimide (PI) using a dip coating method. Consequently, their motor performance and stability are not so high because the line product ratio of the coil is limited due to the existence of vacancy between the coils and because the total electric flux lines are very complex. In contrast, novel coils with rectangular shape wires allow a denser packing and generate homogeneous electrical flux line, which drastically increase their performance and stability. Their edges rectangular coils, however, cannot be covered using conventional insulating coating techniques, such as dipping method, because surface tension 
causes defects in the coatings at the edges, and this problem retards their practical application [2].

Electrodeposition is one of the coating technologies with which charged particles are electrophoresed onto a substrate in an electrolytic cell by implying electric voltage to make defect-free coatings [3]. Therefore, the development of insulating materials with thermostability and facile electrodeposition ability is crucial for the production of high-performance next-generation electric devices. There are some commercially available polyimide materials with electrodeposition ability, but their performance is so limited with which practical application is so restricted [4]. Because few articles have been reported on the development of polyimides with electro-deposition ability in academic journals [5] to our knowledge, development of fundamental study of molecular design and the synthesis of the polyimides with electrodeposition ability is keenly needed from the viewpoint of polymer science.

We have reported that anionic electrodeposition coating was successfully performed using poly(amide acid) nanoparticles, which can be converted to polyimides upon thermal annealing [3]. Hybrid electrodeposition coating using bentonites as inorganic fillers were also obtained and the inorganic content of the electrodeposited film was as high as $40 \%$. The resulting electrodeposition films were thermostable by more than $450{ }^{\circ} \mathrm{C}$. One of the disadvantages of the anionic electrodeposition material is that the PAAs are subjected to hydrolysis in aqueous media, which shortened the pot life of the materials. Therefore, we designed novel solvent soluble polyimide with pendant dimethylaminobenzolyoxy groups which can be ionized by protonation for cationic electrodeposition, and which can be electrodeposited with excellent thermostability, insulating properties, and strong resistance against hydrolysis.

\section{Experimental}

2.1. Apparatus
Electrodeposition was performed using a TEXIO PA250-0.42B as an electric source, and copper plates were used as electrodes. Electrodeposition particles were prepared by a reprecipitation method using a syringe pump YSP-101. ${ }^{1} \mathrm{H}-\mathrm{NMR}$ spectra were recorded with a Bruker Ascend $400 \mathrm{MHz}$ spectrometer using DMSO- $d_{6}$ as a solvent and tetramethylsilane (TMS) as an internal standard. IR spectra were measured with a SHIMADZU IRAffinity-1S spectrometer. Thermal analysis was performed using a Shimadzu DTG-60 at a heating rate of $10{ }^{\circ} \mathrm{C} / \mathrm{min}$ under nitrogen flow (50 $\mathrm{mL} / \mathrm{min}$ ). Particle size and Zeta potential were measured with HORIBA nano partica SZ-100 particle size analyzer.

\subsection{Reagents}

$\mathrm{N}$-methyl-2-pyrrolidone (NMP) was dried over molecular sieves 4A. Boehmite alumina suspension was obtained from Kawaken Fine Chemicals Co., Ltd. Other commercially available reagents were obtained from FUJIFILM Wako Pure Chemical Corporation or from Tokyo Chemical Industry Co., Ltd. (TCI), and used without further purification.

\subsection{Preparation of PI(BTDA/AHPP)}

In a three necked separable flask equipped with nitrogen inlet and calcium chloride tube, AHPP (10.33 g, $40.00 \mathrm{mmol})$ was dissolved in NMP. The flask was cooled in an ice bath, and BTDA (12.89 g, $40.00 \mathrm{mmol})$ was slowly added in 4 portions followed by stirring overnight at room temperature. The resulting varnish was poured into another round bottom flask equipped with a Dean-Stark condenser, which was azeotropic dehydrated in the presence of toluene $(75 \mathrm{~mL})$ for 3 hours. The resulting polyimide was obtained by the reprecipitation in water, and purified twice by the reprecipitation (Fig. 1).

PI(BTDA/AHPP): ${ }^{1} \mathrm{H} \quad$ NMR $\quad[400 \quad \mathrm{MHz}$, DMSO- $\left.d_{6}, 25^{\circ} \mathrm{C}\right]: \delta 1.59\left(\mathrm{~s}, 6 \mathrm{H}:-\mathrm{CH}_{3}\right), 6.90-8.26$ (m, 12H: $-\mathrm{ArH}), 9.72$ (s, 2H: $-\mathrm{OH}$ ). IR: $\tilde{v}=1780$, $1719 \mathrm{~cm}^{-1}$.

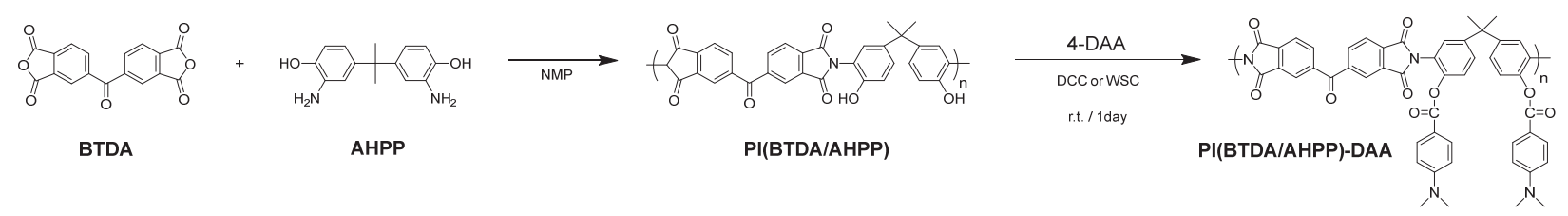

Fig. 1. Scheme of the synthesis of PI(BTDA/AHPP)-DAA with pendant dimethylaminobenzoyloxy groups. 


\subsection{Preparation of $\mathrm{PI}(\mathrm{BTDA} / \mathrm{AHPP})-\mathrm{DAA}$}

PI(BTDA/AHPP) (5.35 g, $9.82 \mathrm{mmol})$ and 4(dimethylamino)benzoic acid (4-DAA) (3.25 g, 19.7 mmol) were dissolved in $35 \mathrm{~mL}$ of NMP and WSC (3.97 $\mathrm{g}, 20.7 \mathrm{mmol}$ ) was added to the solution by stirring overnight at room temperature. The resulting polyimide was obtained by the reprecipitation in water, and purified twice by the reprecipitation (Fig. 1).

PI(BTDA/AHPP)-DAA: ${ }^{1} \mathrm{H}$ NMR [400MHz, DMSO- $d_{6}, 25^{\circ} \mathrm{C}$ ]: $\delta 1.59$ (s, $\left.6 \mathrm{H}:-\mathrm{C}-\mathrm{CH}_{3}\right), 3.05$ (s, 12H: $-\mathrm{N}-\mathrm{CH}_{3}$ ), 6.79 (d, $4 \mathrm{H}$ : $-\mathrm{ArH}, J=9.2 \mathrm{~Hz}$ ), 7.84 (d, 4H: $-\operatorname{Ar} H, J=9.2 \mathrm{~Hz}), 6.69-8.23(\mathrm{~m}$, $-\mathrm{ArH}, 12 \mathrm{H})$. The degree of esterification was $86 \%$ based on the integral ratio of aromatic rings.

\subsection{Electrodeposition procedure}

A PI nanoparticle suspension was poured into a stainless steel cup equipped with the substrate as a cathode, and electrodeposition was performed under stationary voltage conditions. After electrodeposition, the electrodes were dried at room temperature for $10 \mathrm{~min}$, and then baked at 80 , $110,150,170$ and $200{ }^{\circ} \mathrm{C}$ for $30 \mathrm{~min}$.

\subsection{Pinhole test}

A pinhole test solution was prepared by the addition of several droplets of $1 \%$ phenolphthalein solution to $2 \% \mathrm{NaCl}$ aqueous solution. An electric voltage was then applied to an electrolytic bath with the sample as the cathode and a stainless steel plate as the anode. Defects in the insulation coating were monitored through their generation of hydroxide ions, which changes the color of the phenolphthalein indicator.

\section{Results and discussion}

3.1. Preparation of electrodeposition particle of PI(BTDA/AHPP)-DAAH ${ }^{+}$

Since electrodeposition particles were prepared by the addition of poor solvent to the polyimide solution, the solubility of the PI(BTDA/AHPP)DAA in various solvents was investigated to find that the PI(BTDA/AHPP)-DAA was soluble in 1octanol, benzyl alcohol as well as NMP, and insoluble in methanol, ethanol, 1-hexanol, THF, dichloromethane, and water. Based on the results, condition of electrodeposition particle preparation was investigated, which is summarized in Table 1. At first, PI(BTDA/AHPP) was ionized by the addition of lactic acid adjusting the $\mathrm{pH}$ to 4 , which is expressed as $\mathrm{PI}(\mathrm{BTDA} / \mathrm{AHPP})-\mathrm{DAAH}^{+}$, and then water was added as a poor solvent to the PI solution. Addition of only water induced aggregation of PI, therefore, after the PI solution in NMP was diluted by benzyl alcohol to reduce its polarity, water was added. However, partial aggregation was also observed. Changing the benzyl alcohol to methanol or ethanol gave fine dispersion without aggregation after addition of water. Average diameter of the particles was 617 $\mathrm{nm}$, and Zeta potential was $+45 \mathrm{mV}$, showing the formation of stable suspension of PI(BTDA/ AHPP)-DAAH ${ }^{+}$. We also found that fine particles can be obtained by using a homogenizer during the addition of water.

\subsection{Electrodeposition of $\mathrm{PI}(\mathrm{BTDA} / \mathrm{AHPP})-$ \\ $\mathrm{DAAH}^{+}$particles}

Electrodeposition of PI(BTDA/AHPP)-DAAH ${ }^{+}$, which was prepared by the addition of methanol and then the addition of water, was performed at the voltage of $3.9 \mathrm{~V}$ using a cupper electrode as a cathode. Picture of the electrodeposited substrate is shown in Fig. 2(a), where precipitation of PI particles is observed on the surface of the electrode. Figure 2(b) shows the electrode after annealing at $200{ }^{\circ} \mathrm{C}$ for $30 \mathrm{~min}$, in which smooth and dense packed coating layer is observed by the re-solvation and molecular relaxation during the annealing. The electrodeposited coating showed good electric resistance by pinhole test, which was performed by electrolysis in $\mathrm{NaCl}$ solution using the electrodeposited electrode and phenolphthalein as an indicator.

Table 1. Condition of particle preparation of PI(BTDA/AHPP)-DAA.

\begin{tabular}{|c|c|c|c|c|c|c|c|c|c|c|}
\hline \multirow[t]{2}{*}{ run } & \multicolumn{2}{|c|}{$\begin{array}{c}\mathrm{PI}(\mathrm{BTDA} / \mathrm{AHPP})- \\
\text { DAA }\end{array}$} & \multirow{2}{*}{$\begin{array}{l}\text { NMP } \\
(\mathrm{g}) \\
\end{array}$} & \multirow{2}{*}{$\begin{array}{c}\text { PI } \\
(w t \%) \\
\end{array}$} & \multirow{2}{*}{$\begin{array}{c}\text { Benzyl } \\
\text { alcohol } \\
(\mathrm{mL})\end{array}$} & \multirow{2}{*}{$\begin{array}{c}\text { Methanol } \\
(\mathrm{mL})\end{array}$} & \multirow{2}{*}{$\begin{array}{c}\text { Ethanol } \\
(\mathrm{mL})\end{array}$} & \multirow{2}{*}{$\begin{array}{l}\text { Lactic acid } \\
(\mathrm{m} \mathrm{mol})\end{array}$} & \multirow{2}{*}{$\begin{array}{l}\text { Water } \\
(\mathrm{mL}) \\
\end{array}$} & \multirow{2}{*}{$\begin{array}{l}\text { Addition } \\
\text { rate } \\
(\mathrm{mL} / \mathrm{h})\end{array}$} \\
\hline & (g) & $(\mathrm{m} \mathrm{mol})$ & & & & & & & & \\
\hline 1 & 0.42 & 0.5 & 8.3 & 4.8 & - & - & - & 4.4 & 12.0 & 2 \\
\hline 2 & 0.42 & 0.5 & 8.3 & 4.8 & 1.7 & - & - & 6.7 & 10.0 & 2 \\
\hline 3 & 0.20 & 0.2 & 4.2 & 4.5 & - & 3.0 & - & 4.4 & 4.0 & 2 \\
\hline 4 & 0.83 & 1.0 & 16.7 & 4.8 & - & - & 8.0 & 11.1 & 13.0 & 3 \\
\hline 5 & 1.21 & 1.4 & 24.1 & 4.8 & - & - & - & 9.7 & 25.0 & $90 *$ \\
\hline
\end{tabular}



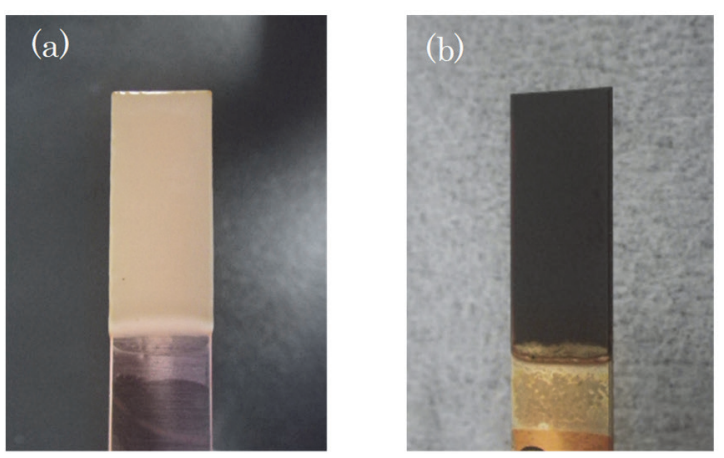

Fig. 2. Pictures of electrodeposited electrodes right after electrodeposition (a) and after annealing at $200{ }^{\circ} \mathrm{C}$ for $30 \mathrm{~min}(\mathrm{~b})$.

Figure 3 shows the change in the electric current during electrodeposition performed at the voltage of $2 \mathrm{~V}-10 \mathrm{~V}$, showing the electric current decreased as the electrodeposition performed. Coulomb efficiency for the coating layer formation was calculated by measuring the weight of precipitates after electrodeposition and the accumulation value of electric currents, shown by the solid circles in Fig. 4. The weight of precipitate grows in proportion to the implied charge, and the coulomb efficiency of electrodeposition coating formation is determined as $3.3 \mathrm{mg}$ /coulomb.

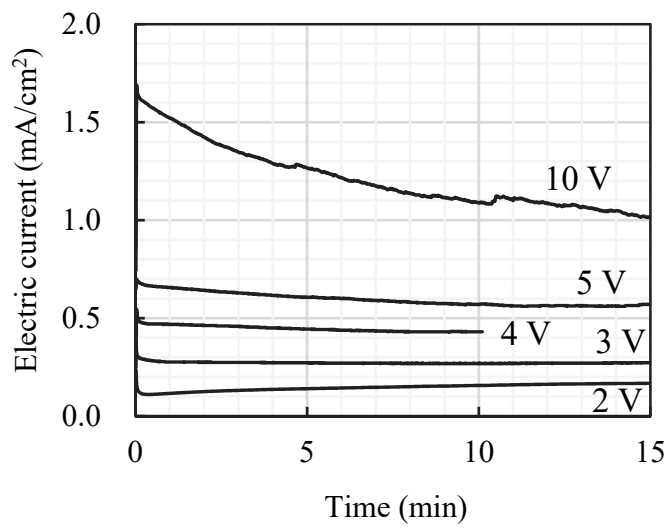

Fig. 3. Change in the electric current during electrodeposition of PI(BTDA/AHPP)-DAA at electric voltage $2 \mathrm{~V}-10 \mathrm{~V}$.

\subsection{Mechanism of electrodeposition of PI(BTDA/} AHPP)-DAAH ${ }^{+}$

The mechanism of electrodeposition of PI(BTDA/AHPP)-DAAH ${ }^{+}$is estimated as the deprotonation by neutralization by hydroxy ion,

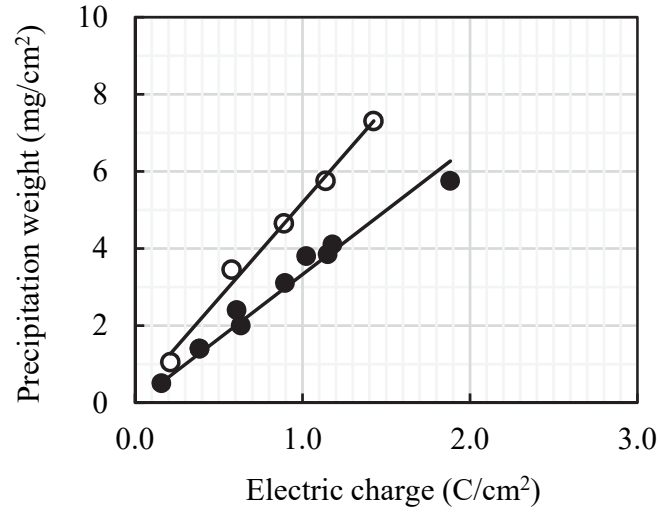

Fig. 4. Change in the precipitation weight during electrodeposition of PI(BTDA/AHPP)-DAAH ${ }^{+}(\bullet)$ and $\mathrm{PI}(\mathrm{BTDA} / \mathrm{AHPP})-\mathrm{DAAH}^{+} / \mathrm{AlOOH}(\mathrm{O})$.

which is generated by the electrolysis of water at cathode. The chemical reaction formulae are shown below.

$2 \mathrm{H}_{2} \mathrm{O}+2 \mathrm{e}^{-} \rightarrow 2 \mathrm{OH}^{-}+\mathrm{H}_{2}$

$$
\begin{aligned}
& \mathrm{PI}(\mathrm{BTDA} / \mathrm{AHPP})-\mathrm{DAAH}^{+}+\mathrm{OH}^{-} \rightarrow \\
& \text { PI(BTDA/AHPP)-DAA }
\end{aligned}
$$

In order to confirm the mechanism, change in the particle size of PI(BTDA/AHPP)-DAAH ${ }^{+}$was measured by the addition of sodium hydroxide solution to change $\mathrm{pH}$ of the solution. Electrodeposition solution was composed of PI(BTDA/AHPP)-DAA (1.44 mmol), NMP (24 $\mathrm{mL})$, lactic acid $(9.71 \mathrm{mmol})$, and water $(25 \mathrm{~mL})$. Figure 5 shows the change in mode radius to relative ratio of $\mathrm{NaOH}$ to the amount of dimethylamino groups, R. The diameter of PI(BTDA/AHPP)-DAAH ${ }^{+}$was $500 \mathrm{~nm}$ before the addition of $\mathrm{NaOH}$, and the diameter become larger after addition of the alkali by 0.5 equivalent of $\mathrm{R}$. The diameter grows up to $2.5 \mu \mathrm{m}$ by the addition of alkali by 1.0 eq. of $\mathrm{R}$, showing that the neutralization of $\mathrm{PI}(\mathrm{BTDA} / \mathrm{AHPP})-\mathrm{DAAH}^{+}$ induced the aggregation of PI(BTDA/AHPP)-DAA. Thus, unstabilized particles deposit on the surface of the substrate to make insulation coatings.

We have measured electron pulse radiolysis spectra of BTDA-containing polyimides using a 35 $\mathrm{MeV}$ linear accelerator to find that radical anion of BTDA group is produced with absorption maxima at $560 \mathrm{~nm}$ and $750 \mathrm{~nm}$ by the recombination of solvated electrons [6,7]. Triplet excited state of BTDA is observed at $520 \mathrm{~nm}$ and charge transfer absorption of a radical cation between BTDA 
cation and chloride anion is observed at $500 \mathrm{~nm}$. Those radical anion or radical cation can be also converted to triplet excited state of BTDA by recombination of electrons. Electronic excited state of BTDA is known to abstract hydrogens from neighboring aliphatic groups [8,9]. An electrode reaction containing those processes may be occurred during the electrodeposition of PI(BTDA/AHPP)-DAAH ${ }^{+}$but the contribution seems to be quite small because the thickness of the electrodeposition coating is as large as more than $150 \mu \mathrm{m}$, which cannot be performed only by the redox reaction on the surface of the electrode. Thus, the neutralization of the protonated PI particle is concluded as the main mechanism of the electrodeposition of PI(BTDA/AHPP)-DAAH ${ }^{+}$.

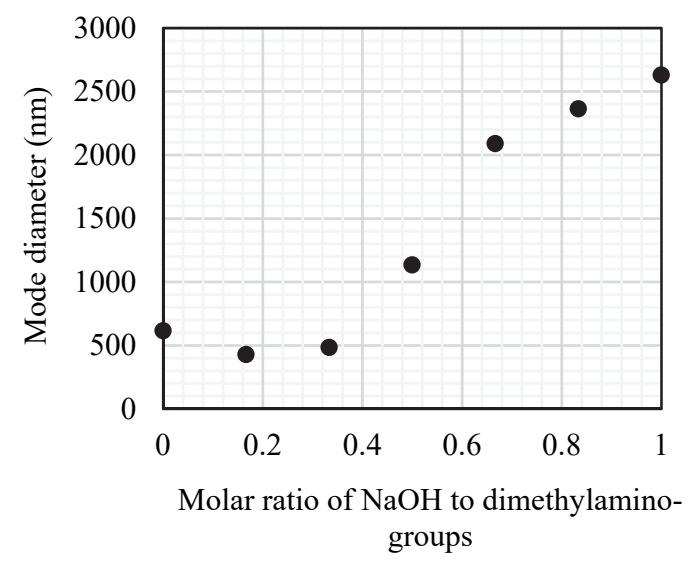

Fig. 5. Change in the mode diameter of PI(BTDA/ AHPP)-DAAH ${ }^{+}$particles by the addition of $\mathrm{NaOH}$.

\subsection{Thermal properties of PI(BTDA/AHPP)-}

$\mathrm{DAAH}^{+}$electrodeposition coating layer

Figure 6 shows the thermogravimetric analysis of the PI(BTDA/AHPP)-DAAH ${ }^{+}$electrodeposition coating layer, removed from the substrate measured under nitrogen flow. The weight of the polymer gradually decreased above $250{ }^{\circ} \mathrm{C}$, and $55 \%$ of the material remains even after annealing at $600{ }^{\circ} \mathrm{C}$. Polymer was completely burned out

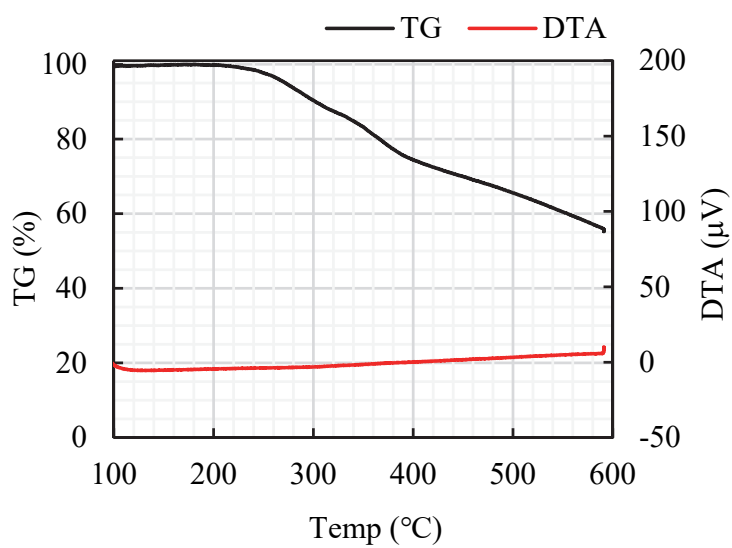

Fig. 6. Thermogravimetric analysis of electrodeposited layer of PI(BTDA/AHPP)-DAAH ${ }^{+}$.

after thermal treatment at $600{ }^{\circ} \mathrm{C}$ in air, and the $10 \%$ weight loss temperature of the electrodeposited coatings was determined as $305^{\circ} \mathrm{C}$.

\subsection{Hybrid electrodeposition of PI(BTDA/AHPP)-}

$\mathrm{DAAH}^{+}$with boehmite alumina

We have found that PI(BTDA/AHPP)-DAAH ${ }^{+}$ can perform electrodeposition by the addition of water to make nanoparticles in the previous section. And so hybrid electrodeposition with boehmite alumina $(\mathrm{AlOOH})$ was investigated because hybridization of polymer with inorganic fillers is known to increase their thermostability and electric surge resistance. Conditions of nanoparticle preparation are summarized in Table 2. Two types of boehmite alumina were investigated, one is dispersed in NMP, and the other is the one dispersed in water. PI(BTDA/AHPP)-DAA was protonated by lactic acid before the addition of boehmite alumina because zeta-potential of the boehmite alumina is $+50 \mathrm{mV}$ and that of PI is negative value, which can induce aggregation by mixing. Boehmite alumina dispersed in water was directly added to PI solution because we expected nano particle formation both by the effect of poor solvent and aggregation with boehmite

Table 2. Condition of hybrid particle preparation of PI(BTDA/AHPP)-DAA and boehmite alumina.

\begin{tabular}{|c|c|c|c|c|c|c|c|c|c|c|c|}
\hline \multirow[t]{2}{*}{ run } & \multicolumn{2}{|c|}{$\begin{array}{c}\text { PI(BTDA/AHPP) - } \\
\text { DAA }\end{array}$} & \multirow{2}{*}{$\begin{array}{l}\text { NMP } \\
(\mathrm{g}) \\
\end{array}$} & \multirow{2}{*}{$\begin{array}{c}\text { PI } \\
(\mathrm{wt} \%) \\
\end{array}$} & \multirow{2}{*}{$\begin{array}{l}\text { Lactic acid } \\
\qquad(\mathrm{mmol})\end{array}$} & \multirow{2}{*}{$\begin{array}{l}\text { Alumna } \\
1.03 \mathrm{wt} \% \\
\text { in NMP } \\
(\mathrm{mL})\end{array}$} & \multirow{2}{*}{$\begin{array}{l}\text { Alumina } \\
1.03 \mathrm{wt} \% \\
\text { in water } \\
(\mathrm{mL})\end{array}$} & \multirow{2}{*}{$\begin{array}{l}\text { Alumina } \\
0.52 \mathrm{wt} \% \\
\text { in water } \\
(\mathrm{mL})\end{array}$} & \multirow{2}{*}{$\begin{array}{l}\text { water } \\
(\mathrm{mL})\end{array}$} & \multirow{2}{*}{$\begin{array}{l}\text { addition } \\
\text { rate } \\
(\mathrm{mL} / \mathrm{min})\end{array}$} & \multirow{2}{*}{$\begin{array}{c}\text { rotation speed } \\
\text { of } \\
\text { homogenizer } \\
(\mathrm{rpm}) \\
\end{array}$} \\
\hline & (g) & $(\mathrm{mmol})$ & & & & & & & & & \\
\hline 1 & 1.22 & 1.5 & 27.0 & 4.3 & 9.0 & 2.01 & - & - & 25.0 & 1 & 6000 \\
\hline 2 & 1.21 & 1.4 & 24.8 & 4.6 & 9.4 & & 25 & - & - & 1 & 6200 \\
\hline 3 & 1.21 & 1.4 & 24.8 & 4.7 & 11.1 & & - & 25 & 10.0 & 1 & 6800 \\
\hline
\end{tabular}


alumina. Electrodeposition solution of PI(BTDA/ AHPP)-DAA/A1OOH was successfully produced in every runs, and the particle size was as small as $380 \mathrm{~nm}$, and zeta potential was $+59 \mathrm{mV}$.

Electrodeposition was performed by electric voltage of $3.8 \mathrm{~V}$ for $15 \mathrm{~min}$, followed by annealing at $200{ }^{\circ} \mathrm{C}$ for $30 \mathrm{~min}$, which gave hybrid electrodeposition coating layer with thickness of $32 \mu \mathrm{m}$. The thickness of deposition coating layer also increased in proportion to electrodeposition time, and the coulomb efficiency of electrodeposition coating formation is determined as 5.2 $\mathrm{mg}$ /coulomb shown by the open circles in Figure 4 . The increase in the coulomb efficiency for the hybrid electrodeposition compared to that without $\mathrm{AlOOH}$ is due to the increase in the number of electrolytes in the solution. Figure 7 shows the thermogravimetric analysis of the hybrid electrodeposition coating measured in nitrogen atmosphere. Content of inorganic filler was calculated by the residual weight after burning organic materials at $600{ }^{\circ} \mathrm{C}$ in air to be $25 \%$. $10 \%$ weight loss temperature is determined as $380{ }^{\circ} \mathrm{C}$, which is higher than that without boehmite alumina by $75^{\circ} \mathrm{C}$.

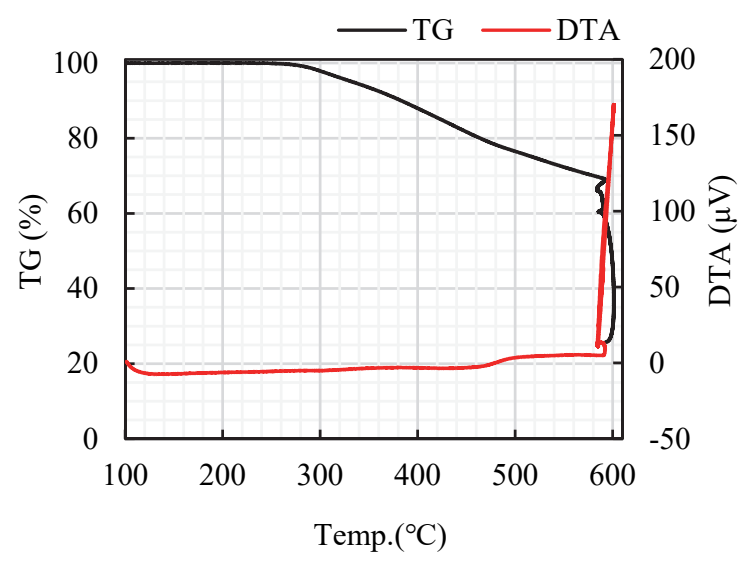

Fig. 7. Thermogravimetric analysis of hybrid electrodeposited layer of PI(BTDA/AHPP)-DAAH ${ }^{+}$ $\mathrm{AlOOH}$.

\section{Conclusion}

A polyimide with pendant dimethylaminobenzoyloxy groups, PI(BTDA/AHPP)-DAA, was synthesized and electrodeposition was performed. Stable nanoparticles of PI(BTDA/ AHPP)-DAAH ${ }^{+}$ was obtained by the addition of methanol and water to the PI solution in NMP, and average diameter of the particles was $617 \mathrm{~nm}$, and Zeta potential was $+45 \mathrm{mV}$. Electrodeposition was successfully performed with the PI nano particles to give insulating layer with coulomb efficiency of electrodeposition coating formation as $3.3 \mathrm{mg}$ /coulomb. The mechanism of electrodeposition of PI(BTDA/AHPP)-DAAH ${ }^{+}$was confirmed as the neutralization by hydroxy ion, which is generated by the electrolysis of water at cathode. The $10 \%$ weight loss temperature of the electrodeposited coating of $\mathrm{PI}(\mathrm{BTDA} / \mathrm{AHPP})-\mathrm{DAAH}^{+}$was determined as $305^{\circ} \mathrm{C}$.

Hybrid electrodeposition coating of PI(BTDA/ AHPP)-DAAH ${ }^{+} / \mathrm{AlOOH}$ was also successfully obtained with coulomb efficiency of $5.2 \mathrm{mg} /$ coulomb, whose $10 \%$ weight loss temperature was $380^{\circ} \mathrm{C}$.

This novel material is advantageous to PAAs because PIs are stable in aqueous media. It is notable that controlling their properties is possible by copolymerization. This material is expected to contribute to the practical application of novel electric motors with high performance and stability and improvement of various next-generation electric devices.

\section{References}

1. N. Hayashizaka, K. Kawasaki, M. Yamashita, T. Ebina, T. Ishida, and S. Hattori, PCT Int. Appl. WO 2017006999 A1 20170112 (2017).

2. Y. Kim, H. Kim, and J. Hong, J. Appl. Polym. Sci., 102 (2006) 5566.

3. A. Kobayashi, H. Wada, M. Yamashita, S. Bando, and T. Yamashita, J. Photopolym. Sci. Technol., 31 (2018) 607.

4. K. Yamazaki, M. Hatta, K. Asao, K. Yamamoto, Y. Yoshioka, and H. Tachi, Jpn. Kokai Tokkyo Koho, JP 2006052268 A 20060223 (2006).

5. S. Nakamura, K. Iida, and G. Sawa, Proc. SPIE, 72 (1996) 2780.

6. T. Yamashita, S. Miake, M. Ogawa, J. Kato, Y. Maekawa, K. Enomoto, Y. Muroya, and K. Katsumura, J. Photopolym. Sci. Technol., 19 (2006) 117.

7. T. Yamashita, T. Kudo, Y. Yoshida, and S. Tagawa, J. Photopolym. Sci. Technol., 18 (2005) 699.

8. H. Higuchi, T. Yamashita, K. Horie, and I. Mita, Chem. Mater, 3 (1991) 188.

9. T. Yamashita, "Photosensitive Polyimides: Fundamental and Applications", K. Horie and T. Yamashita, Eds., Technomic (1996) p.1. 